\title{
Distribution of Galleta Roots and Rhizomes at Two Utah Sites
}

\author{
RUSSELL T. MOORE AND NEIL E. WEST
}

Highlight: Vertical and horizontal distributions of roots and rhizomes were examined in five clones of galleta bisected near Cisco and Cedar City, Utah. Quantity of roots and rhizomes did not differ significantly between the two sites. Although high variability existed among clones at each site, both the root and rhizome systems at Cisco tended to be shallower than at Cedar City. This difference in distribution may result from soil and climatic differences at the two sites.

Although galleta (Hilaria jamesii (Torr.) Benth.) is an important range grass of the arid southwestern U.S., comparatively little is known about the ecology of this species. Western Regional Research Project W-90 (Ecological Life Histories of Selected Western Range Plants) was initiated in 1966 to help fill this void. Part of our contribution to this project was the examination of rooting and rhizome patterns at two sites in Utah.

During the first two years of the W-90 project, little success was achieved in transplanting galleta propagules. We felt that this transplanting difficulty, at least from the two Utah sites, was probably aggravated by a failure to transplant sufficient root mass along the rhizomatic propagule. Thus, we encountered a need for information on rooting and rhizome patterns and their relation to environmental factors and visible plant characteristics.

A comparative scarcity of data on root biomass in the desert grasslands had been noted by IBP Grassland Biome re-

The senior author was NDEA graduate fellow, Range Science Department, Utah State University, Logan. He is presently research associate, Department of Biology, San Diego State College, San Diego, California. Neil West is associate professor, Range Science Department, Utah State Univ.

This contribution of Western Regional Research Project W-90 is listed as Utah Agricultural Experiment Station Technical Paper No. 1193.

Manuscript received October 26, 1971. searchers. The slow decomposition of roots in arid climates confounds the problems of describing the below-ground phytomass. We hope to contribute a bit of quantification for these needs.

\section{Study Areas and Methods}

Galleta in Utah occurs in both the southern Great Basin and Colorado Plateau physiographic provinces. We chose one study site in each province where the species dominated the grass stratum of the plant community.

Our Great Basin site was located $8 \mathrm{~km}$ (5 miles) west of Cedar City, Utah, on a Bureau of Land Management section managed by the Utah Agricultural Experiment Station in cooperation with Southern Utah State College. Relevant climatic data for the Cedar City airport at about 8 $\mathrm{km}$ (5 miles) north at an elevation of $1730 \mathrm{~m}(5700 \mathrm{ft})$ are included in Fig. 1a climatic diagram (Walter, 1963). The soil is classified as a Dixie very fine sandy loam (fine loamy mixed family of xerollic haplargids) on a gently sloping alluvial fan (Soil Conservation Service, Cedar City, personal communication). An approximate $5 \%$ cover of big sagebrush (Artemisia tridentata Nutt.) makes up the shrub component of the plant community on this site.

The Colorado Plateau study site is approximately $11 \mathrm{~km}$ (7 miles) northwest of Cisco, Utah, on Windy Mesa at about $1410 \mathrm{~m}(4600 \mathrm{ft})$ elevation. A climatic diagram for Cisco, 85 meters lower in elevation, is also given in Fig. 1. The soil is a sandy loam phase of the Mesa series (fine loamy mixed family of typic haplargids). West and Ibrahim (1968) gave detailed soil data for similar sites. Widely scattered shadscale (Atriplex confertifolia (Torr.) Benth.) shrubs occur at this site (A. confertifolia-H. jamesii habitat type).

Sheep grazing constitutes the major
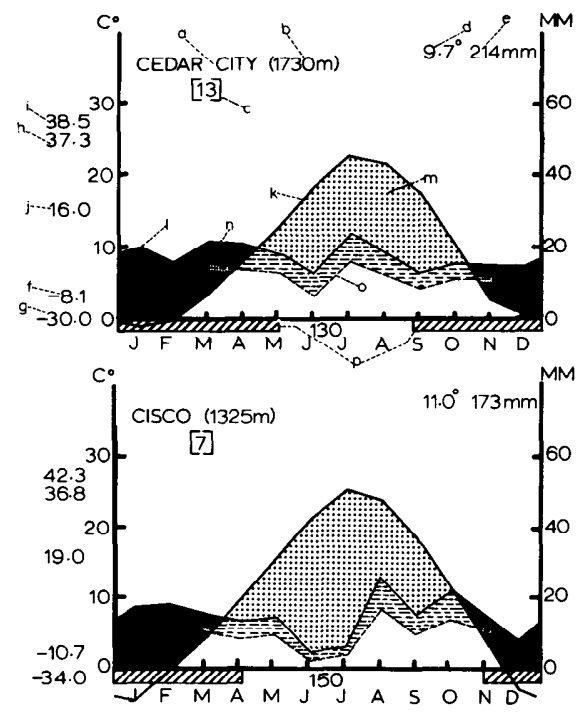

Fig. 1. Climatic diagrams for Cedar City and Cisco, Utah. Explanation of diagrams (after Walter, 1963): a) station, b) altitude, c) number of years of observation, d) mean annual temperature in ${ }^{\circ} \mathrm{C}$, e) mean annual precipitation in $\mathrm{mm}, \mathrm{f}$ ) mean daily minimum of the coldest month, g) absolute minimum, h) mean daily maximum of the hottest month, i) $a b$ solute maximum, j) mean daily temperature range, $k)$ monthly means of temperature in ${ }^{\circ} \mathrm{C}$, l) monthly means of precipitation in $\mathrm{mm}$, m) arid period (dotted), n) humid period (horizontal hatched), o) additional precipitation curve $\left(10^{\circ} \mathrm{C}=30 \mathrm{~mm}\right)$, showing the less extreme dry period, $p$ ) months with an absol. ute minimum below $0^{\circ} \mathrm{C}$. 
forage utilization on both sites, although a few cattle are present throughout most of the growing season at Cisco.

At both Cisco and Cedar City, five galleta clones were selected for sampling in a semi-systematic manner. An effort was made to select clones at least 25 to $50 \mathrm{~m}$ apart which had a north-south diameter no greater than the length of the nail board used.

We recognized at the outset that five clones at each location would hardly represent an adequate sample from which to draw detailed conclusions. However, the high labor requirements associated with each trench precluded the use of a larger sample size.

A modified nail board technique (Schuurman and Goedewoagen, 1965) was used to remove samples of the root and rhizome systems. The board was 240
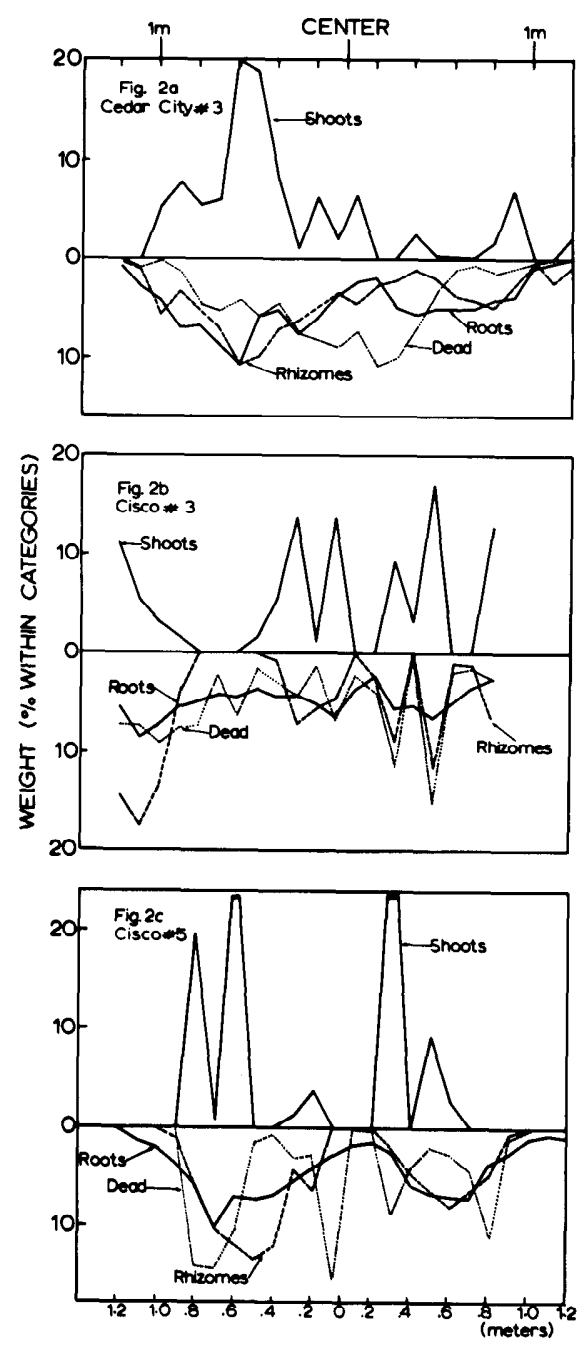

Fig. 2. Horizontal distribution of roots, rhizomes, foliage, and dead material in two typical and one senescent (lower) clone. Horizontal axis represents distance north (left) or south (right) from the center of the clone. Vertical axis represents percentage of the total plant material in a particular category found at that point in the $N$-S transect.

Table 1. Mean dry weight (g) and standard deviations of various plant portions at two Utah sites. ${ }^{1}$

\begin{tabular}{lccrcc}
\hline \hline Site & Roots & Rhizomes & \multicolumn{1}{c}{ Shoots } & Total & Dead \\
\hline Cisco & $28.94 \pm 11.9$ & $27.37 \pm 19.0$ & $8.40 \pm 3.5$ & 64.71 & $24.72 \pm 7.6$ \\
Cedar City & $39.03 \pm 14.5$ & $42.30 \pm 6.5$ & $15.33 \pm 10.3$ & 96.66 & $23.41 \pm 8.6$ \\
\hline
\end{tabular}

${ }^{1}$ Samples correspond to entire profile sampled for $1920 \mathrm{~cm}^{2}$ soil surface area and are means of five clones.

$\mathrm{cm}$ long and $40 \mathrm{~cm}$ deep ( $30 \mathrm{~cm}$ at Cisco) with $8 \mathrm{~cm}$ long nails arranged in a $10 \mathrm{~cm}$ $\mathrm{x} 10 \mathrm{~cm}$ grid.

A north-south trench was cut through each chosen clone to a depth of $50 \mathrm{~cm}$ or until rocks or gypsum layers made further excavation impractical. The trenches were extended to the horizontal limits of root and rhizome spread, although this commonly exceeded the nail board length. The grid of nails was driven into the straightened and smoothed trench wall. Excavation of the second trench in front of the nail tips left a $8 \mathrm{~cm}$ thick section of soil attached to the nail board.

The sample was then removed from the trench and placed in a nearly horizontal position. Soil particles were dislodged and washed away by a fine water spray. Washing continued until all visible soil was removed, leaving the roots and rhizomes in approximately their original position. After the roots and rhizomes dried, they were cut along the grid lines and packaged by sectors. This method of washing allowed sampling of roots to approximately $0.5 \mathrm{~mm}$ diameter and smaller, in some instances.

In the laboratory, the contents of each bag were again washed and separated into rhizome, root, and dead material prior to weighing. The roots and rhizomes were easily differentiated by size and morphology. Dead rhizomes were distinguished by black color, or soft composition, or both. Dead roots were normally characterized by brittleness and decomposition of the cortical tissue. Along the top row of the grid, living and attached dead aerial plant portions were also collected and weighed as "shoots." Unattached litter was not included in the sample.

\section{Results and Discussion}

At both sites, the root spread of most clones substantially exceeded the respective crown diameters. Thus, much of the bare soil between clones is actually occupied by roots. The roots commonly extended $40 \mathrm{~cm}$ beyond the crown in any given direction.

Mean dry weights of roots, rhizomes, shoots, and aggregate dead roots and rhizomes for the five clones at each site are shown in Table 1. In all classes of live material, the Cedar City mean weights exceeded the Cisco mean weights. However, most of the means were accompanied by high variability. Hence, at the $5 \%$ level of significance none of the categories were statistically different for the two sites.

Figure 2 illustrates the horizontal weight distribution of roots, rhizomes, shoots, and aggregate dead roots and rhizomes for two typical clones and one presumably senescent, dead-centered clone. The upper graphs illustrate the irregularity in horizontal distribution of the plant mass both above and below the soil surface. The third graph shows the bimodal distribution pattern common to many larger, and apparently senescent, clones with dead centers.

In Table 2 the weights for the aforementioned categories are separated into percentages within four depth zones. With this separation some important differences appear. The roots at Cisco were most abundant at quite shallow depths while those at Cedar City were more uniformly distributed throughout the profiles examined. Rhizomes and dead material, likewise, tended to be shallower at Cisco than at Cedar City. (Soil surface irregularities and erosion pedestaling

Table 2. Percentage weight distribution of roots, rhizomes, and aggregate dead roots and rhizomes by depth for two Utah sites. ${ }^{1}$

\begin{tabular}{llccr}
\hline \hline Site & Depth & Roots & Rhizomes & Dead \\
\hline Cisco & Crown & 1.7 & 40.4 & 52.2 \\
& $0-10 \mathrm{~cm}$ & 52.5 & 59.6 & 35.9 \\
& $10-20 \mathrm{~cm}$ & 30.7 & - & 8.0 \\
& $>20 \mathrm{~cm}$ & 15.1 & - & 3.9 \\
& Total & 100.0 & 100.0 & 100.0 \\
\multirow{2}{*}{ Cedar City } & Crown & 0.3 & 22.0 & 16.2 \\
& $0-10 \mathrm{~cm}$ & 33.6 & 78.0 & 59.5 \\
& $10-20 \mathrm{~cm}$ & 32.5 & - & 13.2 \\
& $>20 \mathrm{~cm}$ & 33.6 & - & 11.1 \\
& Total & 100.0 & 100.0 & 100.0 \\
\hline 1 Figures represent percentage distribution within each category.
\end{tabular}


caused the inclusion of some roots in the "crown" category at each sitc.)

Chi-squared contingency tables were used to test for differences in distribution between sites and between clones at each site. These tests confirmed the significant (1\% level) difference between mean root distributions at the two sites, but also showed substantial differences among clones at Cedar City and possible differences at Cisco.

Rhizome distribution was significantly different between sites at the $1 \%$ level but the variation among clones at Cisco was also significant. The higher proportion of rhizomes in the crown layer at Cisco could easily result from (1) erosion pedestaling of the clumps, or (2) the greatcr importance of summer precipitation at Cisco (Fig. 1) which would encourage shallower root and rhizome systems.

Distribution of aggregate dead material is different between the two sites as would be expected on the basis of the differences in root and rhizome distributions. Distribution of dead material tended to parallel the rhizome distribution since the rhizomes contribute far greater weight to the "dead" category than do the roots.

Since both the root and rhizome systems at Cisco tended to be shallower than at Cedar City, pedestaling of the Cisco clones would not likely be sufficient to account for the differences in both systems. The differences in root distribution could be the result of differences in soils and/or climate.

The galleta clones at Cisco are found on coarse-textured pediment remnants. The sandy loam soil of the Mesa series overlies a relatively impenetrable clay layer beginning at depths of 20 to $40 \mathrm{~cm}$. Soils are typically non-alkaline and non-saline within the root zone. A $25-40$ $\mathrm{cm}$ thick lime zone begins at depths of $40-75 \mathrm{~cm}$ and the underlying Mancos marine shale is encountered at depths of approximately $125 \mathrm{~cm}$. At Cedar City, the effective root zone is slightly deeper. Here too, the plants are growing in a sandy loam, but the underlying clay is at depths greater than $35 \mathrm{~cm}$. This clay has a moderately developed platy and prismatic structure at various depths and is frequently penetrated by the galleta roots. Although restrictive layers were encountered in both soil profiles they presented a greater barrier to roots at Cisco. We question whether this layer at Cisco is shallow enough, however, to affect the average root and rhizome distribution. From our observations it appears that variation in root distributions among the
Cisco clones is only partially explained by effective soil depth. Although the clone with the shallowest soil depth available $(20 \mathrm{~cm})$ also had a very shallow root system, the clone with the shallowest root system had ample soil depth available (about $30-45 \mathrm{~cm}$ ).

Another explanation for differences in distribution is the site to site difference in the pattern and quantity of precipitation. At Cedar City a large portion of the available moisture results from fall, winter, and early spring precipitation. Thus, the moisture is stored in the soil, and available during most of the growing season. At Cisco precipitation occurs primarily during the latter part of the growing season with resulting high potential evaportation and shallow infiltration. The shallow root and rhizome systems may be adaptations for achieving maximum utilization of the available summer moisture.

The dead root and rhizome material at Cisco represents a substantially higher percentage of the total galleta contribution to biomass $(38.2 \%)$ than does the dead material at Cedar City (24.2\%) (Table 1). This difference is quite likely related to the drier climate and a slower rate of decomposition at the Cisco site.

Although our sample size was inadequate to formulate strong comparisons between the two sites represented, the aforementioned differences existed in the sample and appeared to be reasonably typical of the populations. These differences also appear to be consistent with our expectations based on soils and climatic characteristics of the two sites.

\section{Literature Cited}

Schuurman, J. J., and M. A. J. Goedewoagen. 1965. Methods for the examination of root systems and roots. Centre for Agr. Pub. Wageningen, The Netherlands. 86 p.

Walter, H. 1963. Climatic diagrams as a means to comprehend the various climatic types for ecological and agricultural purposes. In. Rutter, A. J., and F. H. Whitehead (eds.). The Water Relations of Plants, John Wiley and Sons, Inc., New York. p. 3-9.

West, N. E., and K. I. Ibrahim. 1968. Soilvegetation relationships in the shadscale zone of southeastern Utah. Ecology 49:445-456.

\section{6th ANNUAL MEETING SOCIETY FOR RANGE MANAGEMENT RODEWAY INN BOISE, IDAHO FEBRUARY 4-9, 1973}

\author{
Keynote Address: Rangeland and Politics \\ The Honorable Frank Church, United States Senator, Idaho
}

\begin{tabular}{ll}
\multicolumn{1}{c}{ Concurrent Sessions } & \\
$\begin{array}{l}\text { The Rangeman: Ecologist, Manager } \\
\text { or Politician? }\end{array}$ & Range Plant Toxicology \\
Range Improvements & Range Management Systems \\
Youth Range Forum & Rangeland Insects \\
Livestock Grazing on Public Lands & International Range Programs \\
University Student Papers & Range Plant Physiology \\
Remote Sensing of Rangelands & Rangeland Wildlife \\
Communications in Range Management & Rangeland Watersheds \\
Range Plant Ecology & Rangeland Coordination \\
& Rangeland Economics
\end{tabular}

\section{Special Entertainment: Oinkari Basque Dancers}

See December issue of Rangeman's News for details and for room reservation and preregistration forms. 